\title{
Employee Engagement Outlooks in the Era of COVID-19: Implications for Human Resource Management
}

Olawunmi Elizabeth Eniola

University of Regina

Canada

Received: Jan. 13, 2022 Accepted: Feb. 15, 2022 Online published: Feb. 17, 2022

doi:10.5296/ijhrs.v12i1.19462ＵRL: https://doi.org/10.5296/ijhrs.v12i1.19462

\begin{abstract}
The severe COVID-19 pandemic triggered an extraordinary global health crisis, resulting in an economic downturn and negative consequences for employees' work lives, especially employee engagement. An overview of how literature has been tackling the impact of COVID-19 on employee engagement is still missing. Hence, this article illustrates how literature has addressed the development and maintenance of employee engagement in various parts of the world due to the global health crisis. This paper suggests that employee engagement is a function of the interactions involving individual, organization, and the environment. The report discusses individual and organizational roles in fostering employee engagement. The article provides general ideas for researchers interested in extending employee engagement studies under critical situations. It also highlights the consideration for human resource management in both individual and organizational contexts. As well, equips organizational leaders and human resource practitioners with productive and enabling power for informed decision-making about improving employee engagement of their workforce during the ongoing pandemic or other stressful events.
\end{abstract}

Keywords: covid-19, employee engagement, environment, individual, leadership, organization, work-family conflict, work-from-home

\section{Introduction}

\subsection{The Problem}

The COVID-19 pandemic caused psychological pressure and uncertainties that could potentially impact employees' work behavior (De-la-Calle-Durán \& Rodríguez-Sánchez, 2021). Specifically, COVID-19 imposed conditions that were either beneficial or hindered 
employees from bringing greater depths of themselves to the work, roles, and organization. Thus, this literature review examined how the COVID-19 pandemic is connected to employee engagement and the impact of COVID-19 and the work-from-home format on employee engagement.

\subsection{Importance of the Problem}

The COVID-19 pandemic has challenged the typical assumptions about employee engagement. It has created salient challenges that require in-depth inquires and understanding. Researchers have demonstrated that employee success and business success are intricately connected. A highly engaged workforce improves productivity, increases innovation, customer satisfaction, and reduces costs, such as turnover, that directly impact the bottom line (Harvard Business Review, 2020). A Gallup report revealed that companies with a highly engaged workforce have $21 \%$ higher profitability than companies with a disengaged workforce (Harter, 2018). However, in December 2019, a group of deadly coronavirus infections was reported in the Huanan Seafood Market, located in Wuhan State of Hubei Province in China (Sheervalilou et al., 2020). The coronavirus infection that gradually spread worldwide has led to exceptional physical and psychological impacts, i.e., deaths, sicknesses, and societal fear (Sheervalilou et al., 2020). The steps to curtail the spread of the COVID-19 virus caused severe disruptions in workplaces worldwide (Mehta, 2021). The ongoing pandemic caused remarkable changes in business operations and consumer behavior (Donthu $\&$ Gustafsson, 2020). The struggles and challenges triggered by the global health crisis could potentially affect employees' focus, attention, connection, and integration. According to Kahn (1992), personally engaging behavior consists of being attentive, connected, focused, and integrated into organizational roles and work. However, researchers confirmed a plunge in employee engagement at the beginning of the COVID-19 turmoil in the United States (Harris, 2021). As of June 2021, $36 \%$ of U.S. employees are engaged in their work and workplace, while $20 \%$ of employees are engaged at work globally (Harter, 2021).

\subsection{Relevant Scholarship}

Employee engagement is measured individually, aggregated, and reported on the business-unit level (Harter, Schmidt, \& Hayes, 2002). Moreover, scholars contended that the individual employee and not the organization make the decision to be engaged. Shuck and Wollard (2010) noted from the conceptualization of engagement by many authors (Kahn 1990; Harter et al. 2002; Saks 2006; Macey \& Schneider 2008) that employee engagement is a personal decision that cannot be forced or mandated. At the same time, the values embedded in organizational processes and structures shape the emotional and cognitive relationship that individuals develop with their work (Maslach, Schaufeli, \& Leiter, 2001). Shuck and Wollard (2010) suggested that examining employee engagement at the organizational level reveals the health status of an organization. Likewise, both individual and organizational-level precursors are linked to employee engagement during the COVID-19 pandemic.

In addition, the event systems theory indicated that events are parts of the environment or context that is external to the percipient. Events are distinct occurrences that deflect the 
organizational environment's stable or routine features. The strength of events such as novelty, disruption, and criticality move up and down throughout the workplace, leading to changes, new behaviors, features, and events (Morgeson, Mitchell, \& Liu, 2015). Hence, COVID-19 is a novel, disruptive, and critical event that upset the stable organizational environment. COVID-19 events at the environmental level flow through the workplace and affect work behavior, i.e., engagement. Still, COVID-19 is an environmental stimulus that produces adverse effects or behavioral responses, i.e., a low level of engagement for employees (Khan, 2021). Thus, this article proposes that employee engagement is an individual decision that can be influenced by external conditions, e.g., organizational and environmental factors.

In the context of the ongoing COVID-19 crisis, prevailing ecological and social conditions have influenced employee engagement. Therefore, employee engagement is an individual-level construct, and employee engagement experience always occurs within a larger organizational and environmental context. Centered on these assumptions, the organizing mechanism for this literature review was based on COVID-19 and work-from-home format and the individual and organizational level constructs. The direct relationship with COVID-19 or the work-from-home format that became prevalent due to COVID-19 served as the initial delineation in organizing the concepts. The COVID-19 and work-from-home factors were further classified into individual and organizational levels. Hence, a conceptual structure is employed in ensuring clarity and consistency in portraying the main concepts integrated into an overarching idea in this review.

\section{Method}

This literature review synthesized the status of academic research on employee engagement and the COVID-19 pandemic. This study followed the guidelines prescribed by Torraco (2005 \& 2016). A comprehensive review of employee engagement literature was carried out using a multidisciplinary approach that entails literature from management, human resource management and development, psychology, and health. The databases searched included Jstor, Proquest, ABI/Inform, NexisUni, Education database, Science Direct, and Web of Science. The keywords employee engagement, work engagement, COVID-19, employee engagement and COVID-19, COVID-19 and the workplace, work-from-home and engagement, remote work and engagement, teleworking and engagement, COVID-19 and work-from-home were used autonomously to fish for existing literature. The journals were assessed for relevance by examining each abstract. Any articles containing these keywords were downloaded and saved for further review. The literature deemed relevant was read and organized using a spreadsheet. The journal articles that were not relevant were excluded from the study. The exclusion criteria were based on the lack of connection to employee engagement; some articles addressed community engagement, treatment engagement, and only work-from-home and work-family conflict. A total of 63 studies were found suitable and integrated for this literature review. These include three COVID-19 studies, 41 COVID-19 and engagement studies, nine pre-COVID-19 and engagement studies, and ten related studies (e.g., theoretical frameworks, teleworking, and work-family conflict). 


\section{Results}

\subsection{COVID-19 and Employee Engagement}

The COVID-19 pandemic has radically transformed many aspects of society and work-life (Reinwald, Zimmermann, \& Kunze, 2021). For instance, in a study of surgical residents in The Netherlands, residents deployed in a COVID-19 Intensive Care Unit had a lower work engagement of 4.2 compared to a 4.6 level work engagement for residents working in a COVID ward (Poelmann, Koeter, Steinkamp, Vriens, Verhoeven, \& Kruijff, 2021). The daily rising rate of COVID-19 infections has been established as a crucial antecedent to the development of employee engagement. Using the German working population, Reinwald et al. (2021) demonstrated that extreme daily events at the environmental level (i.e., the daily local COVID-19 surge) spill over into the workplace and affect individual daily work behavior, i.e., daily employee engagement. Reinwald et al. (2021) posit that sensemaking is the process through which COVID-19 events' strength impacts the workplace because employees make sense of the daily number of COVID-19 cases reported in their local area.

Similarly, the perceived COVID-19 crisis strength wielded a negative effect on work engagement for medical professionals in China (Liu, Chen, \& Li, 2021). In a study of 12,577 newly hired employees in 3,305 restaurants across the U.S., engagement scores are higher ( $\beta$ $=.03, \mathrm{p}<.05$ ) in States that enforced more rigid COVID-19 restrictions (Ployhart, Shepherd, \& Strizver, 2021). Likewise, extreme anxiety due to COVID-19 mortality salience lowers the level of work engagement of Information Technology employees in both China and the United States (Hu, He, \& Zhou, 2020). Concurrently, other researchers have confirmed the perceived risk of COVID-19 (Moyo, 2020) and COVID-19 pandemic (Ployhart et al., 2021) and their impacts on engagement.

\subsubsection{COVID-19 Individual Level Constructs}

The COVID-19 pandemic has had an overwhelming impact on lives and livelihoods worldwide. The extreme crisis posed unique risks and challenges to individuals. Researchers have examined some of the difficulties triggered by COVID-19 and how they interplay with individual special conditions and means of livelihood. For instance, based on a study of 490 full-time employees in over 20 industries in the United States during the COVID-19 crisis, employees' coping strategies were linked to organizational engagement. In particular, control coping $(\beta=.302, \mathrm{SE}=.07, \mathrm{p}<.001)$ is positively connected with engagement whereas escape coping $(\beta=-.083, \mathrm{SE}=.04, \mathrm{p}=.037)$ is negatively coupled with engagement (Tao, Lee, Sun, $\mathrm{Li}, \& \mathrm{He}, 2021)$.

Besides, in a study of 1033 employees in Austrian organizations during the COVID-19 pandemic, employees' satisfaction with factual corporate information $(\beta=0.27, p<0.001)$ enhances the acceptance of managerial decisions and, in turn, employees' acceptance of managerial decisions has a weak but significant relationship $(\beta=0.11, p<0.05)$ with job engagement. Specifically, employees' acceptance of managerial decisions explained variance of $\mathrm{R}^{2}=0.44$ on job engagement (Einwiller, Ruppel, \& Stranzl, 2021). Equally, Tao et al. (2021) confirmed a linkage between employees' needs satisfaction and organizational 
engagement. Autonomy needs satisfaction $(\beta=.128, \mathrm{p}=.027)$ and relatedness needs satisfaction $(\beta=.222, \mathrm{p}<.001)$ are positively related to engagement while competence needs satisfaction $(\beta=-.076, p=.172)$ is negatively related to engagement.

The impact of mindfulness on work engagement was established through a field experiment in Wuhan, China, during the lockdown (Zheng, Masters-Waage, Yao, Lu, Tan, \& Narayanan, 2020). For ten consecutive days, 55 participants engaged in a 10-min mindfulness practice each morning, and 42 participants in the mind-wandering condition engaged in a 10-min mind wandering practice. The results indicated that participants' sleep duration in the mindfulness condition, compared with the control condition, was less impacted by COVID-19 stressors. Similarly, based on 1302 daily surveys completed in 10 days by participants in the UK, Zheng et al. (2020) concluded that mindfulness nullified the detrimental effect of COVID-19 stressors on sleep duration. Thus, traumatic events such as the COVID-19 pandemic harm employees' sleep. Moreover, Zheng et al. (2020) revealed a positive relationship between sleep quantity and work engagement $(\beta=0.14, p<0.01)$ for both data collected from the experiment and daily surveys. In addition, the indirect effect of COVID-19 stressors on work engagement via sleep quantity was negative and significant when state mindfulness was low and nonsignificant when state mindfulness was high.

A comparative analysis of the mental health status and influence of cultural characteristics between the German and South African workforces revealed a positive association with both groups' mental health shame and motivation during the COVID-19 crisis (Kotera, Mayer, \& Vanderheiden, 2021). At the same time, mental health problems are negatively associated with work engagement and intrinsic motivation in Germans and South Africans. However, German employees had lower mental health problems, mental health shame, and higher self-compassion than South Africans. Kotera et al. (2021) suggested that these differences between Germans and South Africans may likely be explained by the German culture of long-term orientation, uncertainty avoidance, and restraint.

Concurrently, the COVID-19 pandemic negatively impacted work engagement based on a study of 709 participants resuming work after the Spring Festival in China (Song, Wang, Li, Yang, \& Li, 2020). Work engagement was lower than usual because of the impact of mental health due to COVID-19. COVID-19 related mental health issues are from the fear of unemployment which causes anxiety, depression, and insomnia. At the same time, Song et al. (2020) found other positive and independent factors associated with work engagement: age, position, resilience, and optimism. Similarly, psychological distress (mental health issues) due to the work environment lowers the work engagement of health care professionals who were actively working during the COVID-19 pandemic. Nurses were among the highly distressed healthcare workers (Gómez-Salgado, Domínguez-Salas, Romero-Martín, Romero, Coronado-Vázquez, \& Ruiz-Frutos, 2021).

\subsubsection{COVID-19 Organizational Level Constructs}

COVID-19 pandemic has posed critical and unprecedented issues to organizations globally. Organizational responses to the COVID-19 crisis vary and potentially impact the employees' work-life and organizational outcomes. For instance, the employees of state organizations, 
public institutions, social organizations, and foreign-funded enterprises had higher levels of work engagement than the employees of private enterprises in China (Song et al., 2020). Corporate culture and employer-employee relations play essential roles in employee engagement as organizations undergo workplace changes because of COVID-19. Basically, organizational culture identification results in successful employer branding and work engagement based on a study of 402 organizations in the Czech Republic (Urbancová \& Depoo, 2021).

The use of wellbeing centers mitigates the psychological impact of COVID-19 on healthcare workers in the U.K. Work engagement and job satisfaction were high in 819 hospital employees due to access to high-quality rest spaces and psychological first aid (Blake et al., 2020). In a study of 380 foreign employees working in the Hungarian private sector, perceived organizational support significantly influences employee engagement during the COVID-19 pandemic. The findings imply that positive social exchange relationships result in employees' increased attachment and dedication to their organization (Alshaabani, Naz, Magda, \& Rudnák, 2021).

The COVID-19 pandemic moderates the relationship between organizational tenure and new hire engagement in a study of 3,305 restaurants across the United States. The relationship between tenure and engagement was weaker after the pandemic started, and new hire engagement was lower during the COVID-19 pandemic than before, i.e., COVID-19 is negatively related to engagement (Ployhart et al., 2021).

Leaders' motivating languages, e.g., direction giving $(\beta=.267, \mathrm{p}<.001)$ and meaning-making $(\beta=.144, p<.001)$, are positively related to organizational engagement. In contrast, leaders' empathetic language is negatively associated with engagement in various industries in the United States (Tao et al., 2021). In addition, the effect of leaders' direction-giving language or leaders' empathetic language on organizational engagement is mediated first by employees' needs satisfaction (autonomy, relatedness, and competence needs) and then by employees' control coping mechanism (Tao et al., 2021). In accord, servant leadership moderates the harmful effects of COVID-19-triggered mortality salience on job engagement. Servant leaders who show compassion and prioritize employees' wellbeing can help anxious employees remain engaged at work (Hu et al., 2020).

Receiving substantial information increases employees' acceptance of managerial decisions $(\beta=0.41, p<0.001)$, and employees' acceptance of managerial decisions, in turn, stimulates employees' job engagement $(\beta=0.11, \mathrm{p}<0.05)$ in employees of Austrian organizations (Einwiller et al., 2021). In addition, during the COVID-19 crisis, Einwiller et al. (2021) demonstrated that participation $(\beta=0.16, \mathrm{p}<0.01$ ) (listening to and receiving feedback from employees) and communicated appreciation $(\beta=0.42, \mathrm{p}<0.001)$ boost affective organizational commitment while affective organizational commitment, in turn, drives employees' job engagement $(\beta=0.57, \mathrm{p}<0.001)$ in 1033 Austrian employees.

Similarly, based on a study of employees returning to work after the lockdown in various sectors in Wuhan, China, a leader's safety commitment (mask-wearing and temperature monitoring) moderates the relationship between job reattachment and job engagement (Yuan, 
Ye, \& Zhong, 2021). Besides, evidence emerged from the study of 177 employed residents of Matabeleland South Region in Zimbabwe that providing for employees' health and safety needs during COVID-19 will boost employee engagement (Moyo, 2020).

Shin and Hur (2021) confirmed that maintaining work attitudes and behavior in times of COVID-19 crisis depend on perceived organizational health climate (POHC) and leader's health mindset (LHM) based on a study of 301 South Korean employees. POHC indicates the perceptions of organizational policies and practices that support employees' physical and psychological health. The authors established that work engagement mediates the positive relationship between POHC and job crafting during the COVID-19 pandemic. In addition, the leader's health mindset intervened in the positive relationship between POHC and work engagement, i.e., the higher the leader's health mindset, the more positive the connection between POHC and work engagement.

Incentives and benefits helped maintain engagement in 26 Sri Lankan companies. The incentives include curfew allowances, performance allowance, attendance allowance, one-time special COVID allowance, bonuses, recognition programs, free meals and drinks, sanitizing facilities, masks, gloves, health checkups, and avoidance of pay cut (Adikaram, Naotunna, \& Priyankara, 2021).

Meaningful work positively impacts the work engagement of 530 social workers in New Zealand nonprofit organizations during the COVID-19 pandemic (Tan \& Yeap, 2021). Concurrently, work meaningfulness was perceived to mitigate the negative effect of the COVID-19 crisis and engender work engagement for medical staff in an intensive care unit (Liu et al., 2021). The effectiveness of organizational training and interventions alleviated the negative impact of COVID-19 on employees' work engagement and taking charge at work for medical professionals of an intensive care unit (Liu et al., 2021). Still, a high workload can decrease employees' engagement, i.e., workload directly and negatively affect work engagement in a study of 60 employees of four-star hotels in Indonesia during COVID-19 (Fabiyani, Sudiro, Moko, \& Soelton, 2021).

Job insecurity caused by COVID-19 adversely affected employees' engagement in deluxe hotels in South Korea (H. Jung, Y. Jung, \& Yoon, 2020). In an interpretive inquiry, employment insecurity due to COVID-pandemic produced stress that resulted in poor work engagement in U.K. residents working in different sectors (Adisa, Ogbonnaya, \& Adekoya, 2021). Concurrently, the unemployment rate in the United States has a negatively significant relationship with new hire engagement during the COVID-19 pandemic (Ployhart et al., 2021). In a study conducted at Wuhan, China, the epicenter of the coronavirus, job reattachment was positively related to job engagement $(\beta=.37, \mathrm{t}=6.03, \mathrm{p}<.01)$ for employees returning to work (Yuan et al., 2021).

\subsection{Work-From-Home and Employee Engagement}

The COVID-19 pandemic has brought swift, enormous, and disruptive changes to the world of work and has altered the workplace forever. Many categories of work have been shifted to the work-from-home format depending on the nature of the work (Mehta, 2021). However, 
working from home has posed new challenges and risks. The lines between work and private lives blur due to the work-from-home (WFH) format. In addition, employees struggle with their work-life boundaries. The work-home boundary violation accounts for unfinished tasks in both work and home domains and results in dissatisfaction in both domains (Kerman, Korunka, \& Tement, in press).

\subsubsection{Work-From-Home Individual Level Constructs}

Specific attributes make a person unique and regulate their effectiveness in a job role. These attributes might be different even for people with similar education and experience. Researchers found that personal resources possibly contribute to efficient remote work. For example, personality traits that were usually associated with desirable outcomes were responsible for deteriorating results for remote workers during the COVID-19 outbreak based on a four-wave longitudinal study of 974 remote workers in the United Kingdom (Evans, Meyers, Van De Calseyde, \& Stavrova, 2021). Extroverted and conscientious employees became less productive, less engaged, and less satisfied with their jobs. This finding emphasized that certain personality traits may be beneficial or detrimental for job outcomes under rapidly changing external events (Evans et al., 2021).

Gender differences impacted work engagement among 785 work-from-home employees in 170 randomly selected Slovenian companies during the COVID-19 pandemic. There was a statistically significant difference in work engagement among employees by gender (Rožman, Sternad Zabukovšek, Bobek, \& Tominc, 2021). Expressly, Rožman et al. (2021) specified that during the COVID-19 work-from-home, the work engagement indicators are perceived lower in female employees than in male employees.

In addition, studies have suggested that individual resources hinder and facilitate WFH during the COVID-19 outbreak. For instance, self-efficacy and resilience impacted work engagement based on a survey of 259 respondents working in the knowledge-based sectors, e.g., higher education, information technology, and engineering services during Malaysia's COVID-19 movement control order (MCO) period (Ojo, Fawehinmi, \& Yusliza, 2021). Specifically, employees' self-efficacy is positively related to resilience, while resilience mediates the effect of employees' self-efficacy on work engagement. Thus, employees who are highly confident in performing job tasks can recoup rapidly from stress provoked by a global pandemic like COVID-19. Resilience is positively connected with work engagement. Therefore, employees must develop the personal resources of resilience, which fosters optimism, tenacity, and strength when faced with difficulties (Ojo et al., 2021).

Self-leadership is one of the personal resources for engagement, i.e., the resources of self-leadership $(\beta=0.23 ; \mathrm{P}<0.01)$ are positively related to work engagement (Galanti, Guidetti, Mazzei, Zappala, \& Toscano, 2021 p. 429). The perception of autonomy during COVID-19 work-from-home significantly impacts employees' work engagement in the information technology sector in India (Mehta, 2021). In a study of 209 Italian employees with children, the resource of autonomy $(\beta=0.19$; $\mathrm{P}<0.01)$ was found to be positively related to work engagement (Galanti et al. 2021 p. 429). 
The WFH constructs, convenience, and psychosocial safety accounted for a $25.2 \%$ variance in WFH work engagement during the COVID-19 pandemic. Specifically, work-from-home psychosocial safety is related to WFH work engagement, and the remote work during COVID-19 significantly impacts employees' happiness (Mehta, 2021 p. 8). Based on a study of full-time lecturers working from home in five Malaysian research universities during the COVID-19 crisis, job resources and psychosocial safety explained a $25.3 \%$ variance in work engagement. Job resources are positively related to work engagement, psychosocial safety is not significantly associated with work engagement, and job resources mediate the relationship between psychosocial safety and work engagement (Gan \& Kee, 2021).

Nguyen and Tran (2021) reported that employees with a high degree of perceived family support (PFS) are more motivated in the workplace. Perceived spousal and family members' support impact employee engagement in 206 participants from 10 organizations in Vietnam. However, the effect size of the perceived family support on employee engagement is small due to the COVID-19 pandemic. Adisa et al. (2021) found that poor adaptation to new ways of working from home during the COVID-19 lockdown has debilitating effects on the work engagement of residents in the United Kingdom. Galanti et al. (2021) confirmed that the reduction or lack of the social context that employees generally experience in the workplace, i.e., social isolation $(\beta-0.36 ; \mathrm{P}<0.01)$, is negatively related to work engagement.

In a recent study on COVID-19 and work-from-home (WFH), remote work resulted in a high level of work-family conflict in workers in Guayaquil, Ecuador. Remote work saved time spent commuting but presented discomfort and conflict between home and work responsibilities. The work-family conflict manifested in greater exhaustion (Barriga Medina, Campoverde Aguirre, Coello-Montecel, Ochoa Pacheco, \& Paredes-Aguirre, 2021). The struggle of effectively reconciling private and work commitments, such as family-work conflict $(\beta=-0.19 ; \mathrm{P}<0.01)$ and distracting work environment $(\beta=-0.18 ; \mathrm{P}<0.05)$, are negatively related to work engagement (Galanti et al., 2021, p. 429). Female employees have a higher level of engagement than male employees working from home during the COVID-19 pandemic in India. However, a higher number of children decreases the engagement of remote workers (Chaudhary, Mohanty, \& Malik, 2021).

Conversely, based on a study of 25 employees forced to work exclusively from home during COVID-19, the COVID-19 imposed WFH could improve employee engagement or cause adverse effects, e.g., work-family conflict and homesickness. Working from home could adequately replace traditional work arrangements. However, prolonged working from home could impede employee engagement and employee experience to the point of burnout (De Klerk, Joubert, \& Mosca, 2021). According to De Klerk et al. (2021), job resources and demands regulate the WFH experience. On the one hand, higher employee engagement is achieved if job resources (e.g., organizational support) exceed job demands. On the other hand, adverse experiences and decreased engagement will occur if job demands (e.g., increased workload and family commitments) exceed job resources. Thus, working from home for lengthy periods triggers paradoxical outcomes.

Khan's (2021) findings added significant thought to the exploration. Based on a study of 
teachers from government schools in Pakistan, perceived COVID-19 threat, misinformation, and social media fatigue reduced the work engagement of 92 teachers working from home and performing both teaching and administrative duties. Explicitly, environmental stimuli or stressors such as COVID-19 threats and social media misinformation caused strain (anxiety and social media fatigue) which produced adverse effects or behavioral responses (low level of engagement) for employees working from home. Similarly, in a four-wave study of 965 employees working remotely in Finland, increased psychological distress is associated with decreased work engagement (Oksa, Kaakinen, Savela, Hakanen, \& Oksanen, 2021).

\subsubsection{Work-From-Home Organizational Level Constructs}

Beyond the WFH individual factors, studies have explored WFH-organizational and work-related factors and practices responsible for employee engagement during the COVID-19 pandemic. The perception of leadership and team support has been linked to the development of employee engagement. Leadership behavior and team effectiveness are directly related to remote workers' engagement during the COVID-19 pandemic in South Africa (Koekemoer, De Beer, Govender, \& Brouwers, 2021). Supervisor support $(\beta=0.125$, $\mathrm{p}<0.05)$ and coworker support $(\beta=0.466, \mathrm{p}<0.05)$ positively impacted psychological contract fulfillment and in turn psychological contract fulfillment positively impacted the work engagement $(\beta=0.767, p<0.05)$ of 239 employees working from home in the sales department of durable consumer industries in India (Karani \& Mehta, 2021).

Organizational support (colleague support and supervisor support) is vital in retaining work engagement when working from home during the COVID-19 lockdown in Vietnam (Nguyen \& Tran, 2021). According to Nguyen and Tran (2021), in the Asian context, supervisor support plays a more significant role than colleague support because junior employees are inclined to follow and wait for detailed instruction and support from senior managers. Similarly, supervisor support, facilitating conditions (technology platforms), and resilience facilitate work engagement during Malaysia's COVID-19 movement control order (MCO) (Ojo et al., 2021). In addition, supervisor support and facilitating conditions (technology platforms) are positively connected to resilience. Though supervisor support was not significantly associated with employees' resilience. This finding could be due to the grim and unusual situation of COVID-19, which may cause intense psychological anxieties. Still, resilience mediates the effect of supervisor support and facilitating conditions (technology platforms) on work engagement (Ojo et al., 2021).

Increased social media communication, perceived social support, and task resources predict increased work engagement in a four-wave study in Finland (Oksa et al., 2021). This conclusion is consistent with the findings that proper virtual tools, contact by the organization leaders, mental health checkups, and virtual training increased the WFH engagement of employees during COVID-19 across different states in India (Chaudhary et al., 2021). However, Chaudhary et al. (2021) found that virtual teamwork and entertainment tools (e.g., online yoga and virtual quizzes) had no significant impact on WFH engagement. Chanana and Sangeeta (2020) suggested that work-from-home regime engagement activities efficiently drive employee engagement during tough times, e.g., family engagement, virtual learning, 
and development, online team building activities, webinars, virtual challenges, and competitions, online counseling sessions, recognition, etc.

Chen and Sriphon (2021) offered distinct evidence that highlighted the significance of leadership and the debilitating effect of COVID-19 on organizational leadership by using data collected from 220 managers of various organizations in Thailand, Vietnam, Indonesia, and Taiwan. COVID-19 impacted organizational leadership, consequently impacting employee engagement. Chen and Sriphon (2021) demonstrated that remote work interrupted the trust and relationships (both communal and social exchange relationships) between employees and managers during the pandemic. Specifically, managers implemented more controls and monitoring of employees working remotely. Consequently, COVID-19 diminishes the quality of leadership in organizations.

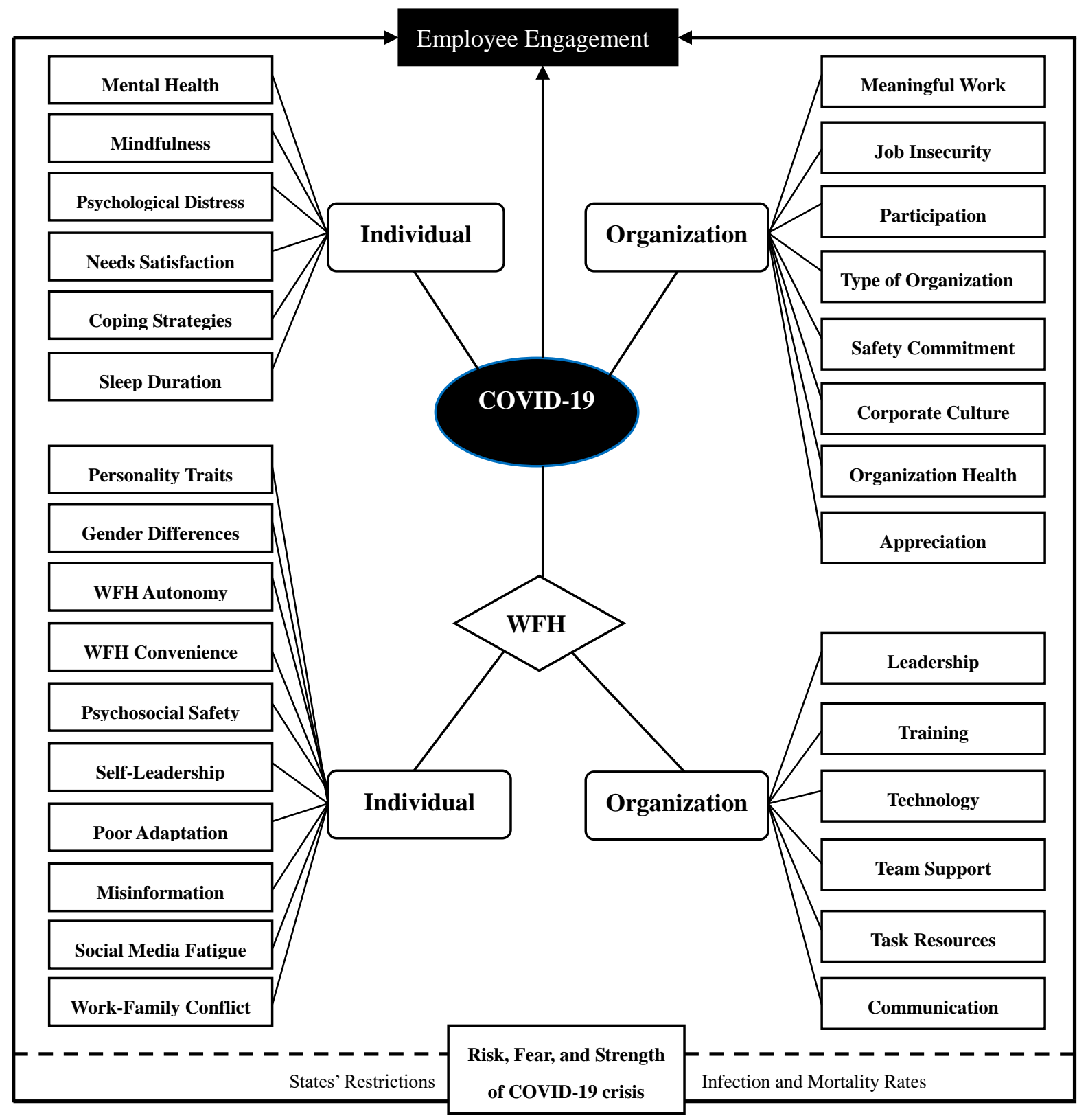

Figure 1. Employee Engagement and COVID-19 


\section{Macrothink}

\section{Discussion}

This article illuminates the relationship between COVID-19 and the cultivation of employee engagement. The COVID-19 era heralded a new approach and assumptions in examining the concept of employee engagement. Figure one depicts the overall outlooks of employee engagement during the COVID-19 pandemic. The article has made connections to research that indicated that employee engagement is an individual-level decision and to research that emphasized that organizational conditions are essential in maintaining and developing employee engagement. The study has established that both individual and organizational variables precede employee engagement. In addition, this study confirmed that environment or environmental events, e.g., COVID-19 and work-from-home, impact employee engagement. Thus, this study proposes that employee engagement is an individual-level construct, and employee engagement experience always occurs within a larger organizational and environmental context, i.e., employee engagement is influenced by organizational and environmental conditions. Thus, employee engagement (EE) is a function of the interaction involving individual (i), organization (o), and the environment (e), and this is represented as follows:

$$
E E=f(i, o, e)
$$

The development and maintenance of engagement depend on a tripartite relationship involving the individual, organization, and the environment (e.g., COVID-19, work-from-home format). Figure two depicts the relationship and outlooks of employee engagement. In essence, thinking about employee engagement in the era of COVID-19 requires considering how the individual, organization, and the environment form a tripartite relationship that triggers or deplete engagement. This study contributes to the engagement literature by establishing that the environment is an essential determining factor of employee engagement and employee engagement depends mainly on the threefold relationship involving the environment, individual, and organization.

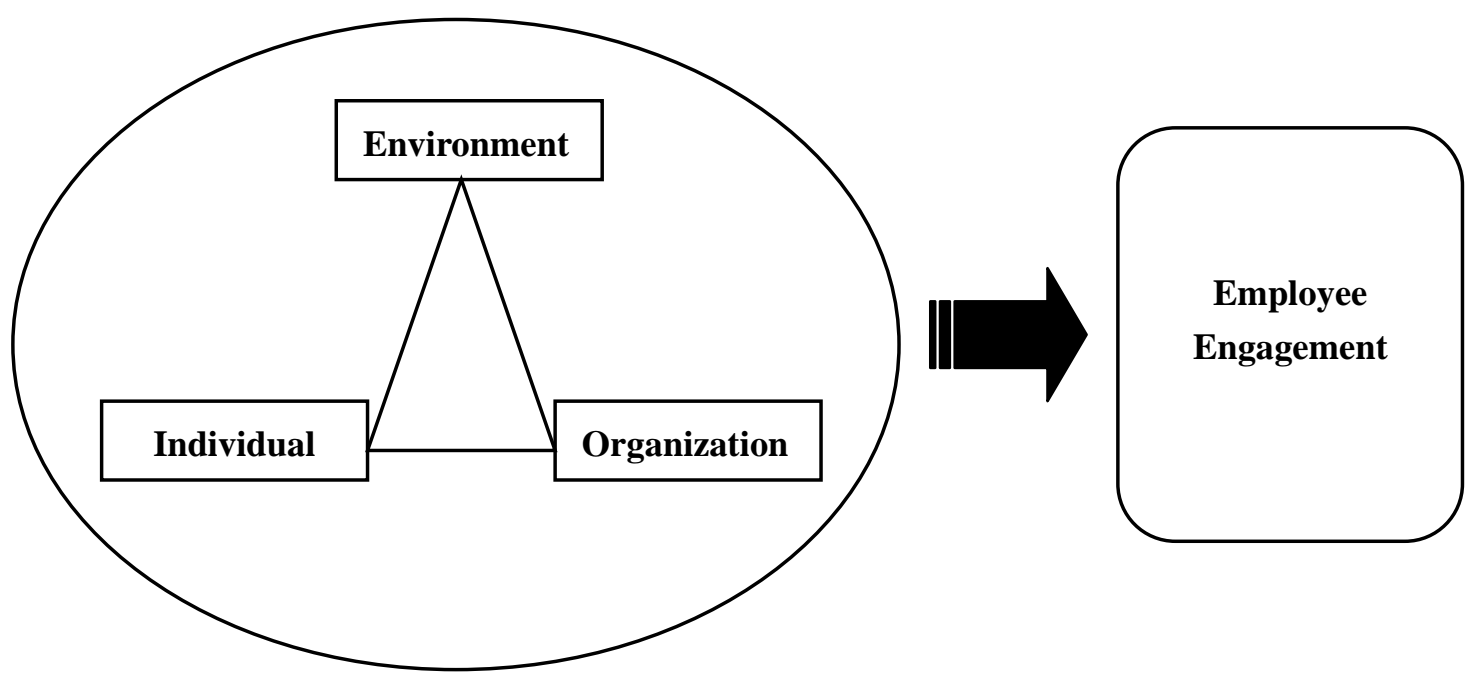

Figure 2. Employee Engagement Outlook 


\section{Mll Macrothink}

International Journal of Human Resource Studies

ISSN 2162-3058

2022, Vol. 12, No. 1

The two prominent organizational and individual constructs are leadership and work-family conflict. In the era of COVID-19, leadership plays a crucial role in maintaining employee engagement. Everything rises and falls on leadership (Maxwell, 2007). The design of jobs, flexible work arrangements, ensuring effective communication, safety at work, providing support, and promoting enabling conditions, e.g., psychological safety, technology, virtual tools, task resources, etc., are dependent on leadership. Similarly, many authors have touted leadership as an indispensable means of influencing engagement (Caulfield \& Senger, 2017; Stander, De Beer, \& Stander, 2015). In addition, family-supportive supervision, e.g., emotional and instrumental support, creative work-family management, and role models for work-life balance, has been deemed a beneficial job resource relevant in lowering work-family conflict and improving wellbeing (Walsh, Matthews, Toumbeva, Kabat-Farr, Philbrick, \& Pavisic, 2019). At the same time, a lack of family-supportive supervision may activate negative social responses such as ostracism from employees (Walsh et al., 2019).

Undoubtedly, COVID-19 transformed the typical workplace globally and erased the home-work separation. The work-from-home format has contradictory outcomes for employee engagement. It comes with the benefit of saving commute time, getting more work accomplished, and promoting safety during the crisis. Yet it is a significant contributor to work-life balance problems. For instance, engagement levels decline because of work-family conflict due to family size, distracting work environment, and boundary transition issues for those unable to psychologically detach from work as appropriate. This situation aligns with the notions of the work-family conflict model (Greenhaus \& Beutell, 1985) that inter-role conflict between work and private life occurs when working from home because of incompatible pressures from both work and personal life. The conclusions are also in accord with findings that boundary violations happen in the work-family interface, which may produce positive or negative outcomes (Hunter, Clark, \& Carlson, 2019). Specifically, boundary violations caused general perceptions of work-family conflict both directly and indirectly. The violations occur when employees are interrupted from their task in either the work or home domain to handle another work or home domain task or interact with another domain participant. Moreover, this positive or negative outcome is due to the individual's cognitive processing of the event as either impeding or enabling one's goals (Hunter et al., 2019).

\subsection{Theoretical Implications for Human Resource Management}

The development of employee engagement occurs at the individual level within the operation of internal and external environmental and organizational conditions. Shuck and Wollard (2010) stated that employee engagement is an individual-level variable frequently evaluated at the organizational level. Indeed, it is worthwhile to explore engagement on the organizational level. At the same time, the debilitating effects of COVID-19 necessitate a unique approach toward assessing and cultivating employee engagement on the individual level because the impact of COVID-19 on employees' work lives varies from person to person. For instance, resilience, mindfulness, mental health, psychological distress, and sleep duration have been identified as essential antecedents to engagement under the ongoing COVID-19 crisis. However, the operation of these constructs is unique to individuals. In the 
context of COVID-19, the uniqueness of employee engagement to individuals is validated by the conservation of resource theory (Hobfoll, $1989 \&$ 2011) that "people must invest resources to protect against resource loss, recover from losses, and gain resources" (Hobfoll, 2011 p. 117). Some of the resources identified in the conservation of resource theory by Hobfoll (2011 p. 117) are personal resources (e.g., essential skills and personal traits such as self-efficacy and self-esteem), condition resources (e.g., supportive work relationships), and energy resources (e.g., knowledge, credit). In essence, people draw on resources to cope with stressors, and the inability to cope might result in the consumption of too many resources. Thus, how people react to stressors (COVID-19) in their environment might influence their wellbeing and, in turn, affect employee engagement. Concurrently the tenets of the transactional model of stress and coping by Lazarus and Folkman (1984) emphasized that individuals have different approaches toward the appraisal of stressors and selection of coping strategies.

\subsection{Practical Implications for Human Resource Management}

The overarching idea is that organizations that are supportive and can balance business needs cum employee needs undoubtedly have an engaged workforce during the pandemic. Specifically, authors have highlighted the detrimental effects of monitoring employees working remotely at the expense of creating more psychological distress and destroying employee-manager relationships. In addition, buffering job demands through job resources is a critical and unavoidable requirement for organizations that will sail through the pandemic successfully. Baker and Demerouti (2008) indicated that job resources, e.g., performance feedback, social support, and supervisory coaching, stimulate a motivational process that increases engagement. However, "high job demands, e.g., workload, emotional demands, and mental demands deplete employees' physical and mental resources and lead to the increased stress that can cause disengagement. Concurrently, daily job resources, e.g., supervisory coaching and team atmosphere enhanced employees' personal resources, e.g., day-levels of optimism, self-efficacy, and self-esteem, which, in turn, account for daily engagement (Xanthopoulou, Bakker, Demerouti, \& Schaufeli, 2009). In the light of the COVID-19 threats, risks, anxieties, mortality, work-family conflict, and social isolation due to the work-from-home format, organizations must enable psychological conditions and resources that will alleviate the detrimental effects of the raging COVID-19 on employees work and job demands.

Further, there is a need for a good structure and systems to promote job resources in organizations. Job resources could be fostered through organizational policies, practices, and traditional face-to-face work and remote work strategies. Such techniques include designing employee support programs that facilitate focus and engagement, learning and developmental opportunities that promote optimism, self-efficacy, and resilience, well-defined work-from-home practices and policies, and clear and transparent WFH performance metrics.

This article has unraveled salient conditions for an engaged workforce in the face of the battle with the unabating COVID-19 pandemic. Knowing the possible predictors of engagement will aid in conducting a proper analysis of organizational issues. This article equips 
organizational leaders and human resource practitioners with the knowledge that will be valuable in examining the engagement states of their workforce.

\subsection{Recommendation for Future Research}

A large number of the COVID-19 and employee engagement studies have focused on the numerous precursors of employee engagement. Most of these studies employed a one-time cross-sectional approach, while a few studies utilized two weeks dairy studies. However, due to the enormity of the coronavirus pandemic and the indications that COVID-19 may become a lifespan issue because of its persistent nature, it would be beneficial to use longitudinal techniques to study engagement during the COVID-19 crisis. It could be that a shift may occur over time in some of the ideas and beliefs currently identified by research. This article proposes that researchers look for changes over time regarding coping strategies and mindfulness, as they may change over time. For instance, Lazarus and Folkman (1984) indicated that coping strategies are dependent on personal variables (e.g., beliefs, self-esteem, social support, economic status, and motivation) and environmental variables (e.g., demands, constraints). This article speculates that these personal and environmental variables are also susceptible to changes over time. In addition, work-from-home constructs of engagement such as work-family conflict and isolation deserve extensive attention over a prolonged period of time. For instance, employees' approaches to boundary transitions may change at different points in life. As Hunter et al. (2019) indicated, boundary violation is a crucial player in the work-family conflict, and this article surmises that boundary transition is a pivot of work-life balance.

\subsection{Limitation of Study}

The study is based on available publications on COVID-19 and employee engagement at the investigation time. However, newer studies are being conducted day-to-day about COVID-19 and employee engagement. Much research is focusing on COVID-19 due to the pandemic's magnitude and incessant nature. Thus, this literature review may not capture all the constructs, conditions, and strategies responsible for developing and maintaining employee engagement during the ongoing COVID-19 crisis.

\section{Acknowledgments}

This acknowledgment goes to the University of Regina for providing research resources.

\section{References}

Adikaram, A. S., Naotunna, N. P., \& Priyankara, H. P. R. (2021). Battling COVID-19 with human resource management bundling. Employee Relations: The International Journal, 43(6), 1269-1289. https://doi.org/10.1108/ER-08-2020-0390

Adisa, T. A., Ogbonnaya, C., \& Adekoya, O. D. (2021). Remote working and employee engagement: A qualitative study of British workers during the pandemic. Information Technology and People, 1-16. https://doi.org/10.1108/ITP-12-2020-0850

Alshaabani, A., Naz, F., Magda, R., \& Rudnák, I. (2021). Impact of perceived organizational 
support on OCB in the time of COVID-19 pandemic in Hungary: Employee engagement and affective commitment as mediators. Sustainability, 13(7800), 1-21. https://doi.org10.3390/su13147800/

Bakker, A. B., \& Demerouti, E. (2008). Towards a model of work engagement. Career Development International, 13(3), 209-223. https://doi.org/10.1108/13620430810870476

Barriga Medina, H. R., Campoverde Aguirre, R., Coello-Montecel, D., Ochoa Pacheco, P., \& Paredes-Aguirre, M. I. (2021). The influence of work-family conflict on burnout during the COVID-19 pandemic: The effect of teleworking overload. International Journal of Environmental Research and Public Health, 18(10302), 1-22. https://doi.org/10.3390/ijerph181910302

Ben-Zur, H. (2020) Transactional model of stress and coping. In: Zeigler-Hill V., Shackelford T.K. (eds) Encyclopedia of Personality and Individual Differences. Springer, Cham. Retrieved December 11, 2021, from https://doi-org.libproxy.uregina.ca/10.1007/978-3-319-24612-3_2128

Blake, H., Yildirim, M., Wood, B., Knowles, S., Mancini, H., Coyne, E., \& Cooper, J. (2020). COVID-Well: Evaluation of the implementation of supported wellbeing centres for hospital employees during the COVID-19 pandemic. Internal Journal of Environmental Research and Public Health, 17(9401), 1-22. https://doi.org/10.3390/ijerph17249401

Caulfield, J. L., \& Senger, A. (2017). Perception is reality: Change leadership and work engagement. Leadership \& Organization Development Journal, 38(7), 927-945. https://doi.org/10.1108/LODJ-07-2016-0166

Chanana, N., \& Sangeeta. (2020). Employee engagement practices during COVID-19 lockdown. Journal of Public Affairs, 1-18. https://doi.org/10.1002/pa.2508

Chaudhary, V., Mohanty, S., \& Malik, P. (2021). Factors affecting virtual employee engagement in India during Covid-19, Materials Today: Proceedings, 1-5. https://doi.org/10.1016/j.matpr.2021.05.685

Chen, J. K. C., \& Sriphon, T. (2021). Perspective on COVID-19 pandemic factors impacting organizational leadership. Sustainability, 13(3230), 1-21. https://doi.org/10.3390/su13063230

De Klerk, J. J., Joubert, M., \& Mosca, H. F. (2021). Is working from home the new workplace panacea? Lessons from the COVID-19 pandemic for the future world of work. $S A$ Journal of Industrial Psychology/SA Tydskrif virBedryfsielkunde, 47(0), 1-14. https://doi.org/10.4102/sajip.v47i0.1883

De-la-Calle-Durán, M. C., \& Rodríguez-Sánchez, J. L. (2021). Employee engagement and wellbeing in times of COVID-19: A proposal of the 5Cs model. International Journal Environmental Research and Public Health, 18(5470), 1-15. https://doi.org/10.3390/ijerph18105470

Donthu, N., \& Gustafsson, A. (2020). Effects of COVID-19 on business and research. Journal of Business Research, 284-289. https://doi.org/10.1016/j.jbusres.2020.06.008 


\section{Ml Macrothink}

International Journal of Human Resource Studies ISSN 2162-3058 2022, Vol. 12, No. 1

Einwiller, S., Ruppel, C., \& Stranzl, J. (2021). Achieving employee support during the COVID-19 pandemic - The role of relational and informational crisis communication in Austrian organizations. Journal of Communication Management, 25(3), 233-255. https://doi.org/10.1108/JCOM-10-2020-0107

Evans, A. M., Meyers, C., Van De Calseyde, P. F. M., \& Stavrova, O. (2021). Extroversion and conscientiousness predict deteriorating job outcomes during the COVID-19 transition to enforced remote work. Social Psychological and Personality Science, 1-11. https://doi.org/10.1177/19485506211039092

Fabiyani, N. N., Sudiro, A., Moko, W., \& Soelton, M. (2021). Conceptualizing the role of work engagement: A case study of the hotel sector in Surabaya during the COVID-19. Journal of Asian Finance, Economics and Business, 8(5), 485-494. https://doi.org/10.13106/jafeb.2021.vol8.no5.0485

Galanti, T., Guidetti, G., Mazzei, E., Zappala, S., \& Toscano, F. (2021). Work from home during the COVID-19 outbreak: The impact on employees' remote work productivity, engagement, and stress. Journal of Occupational and Environmental Medicine, 63(7) 426-432.

Gan, K. H., \& Kee, D. M. H. (2021). Psychosocial safety climate, work engagement and organizational commitment in Malaysian research universities: The mediating role of job resources. Foresight, 1-14. https://doi.org/10.1108/FS-01-2021-0019

Gómez-Salgado, J., Domínguez-Salas, S., Romero-Martín, M., Romero, A., Coronado-Vázquez, V., \& Ruiz-Frutos, C. (2021). Work engagement and psychological distress of health professionals during the COVID-19 pandemic. Journal of Nursing Management, 29, 1016-1025.

Greenhaus, J. H., \& Beutell, N. J. (1985). Sources of conflict between work and family roles. The Academy of Management Review, 10(1), 76-88.

Harris, G. (2021, July 17). The impact of COVID-19 on employee engagement. Quantum Workplace, 148586611, 1-3.

Harter, J. K., Schmidt, F. L., \& Hayes, T. L. (2002). Business-unit-level relationship between employee satisfaction, employee engagement, and business outcomes: A meta-analysis. Journal of Applied Psychology, 87(2), 268-279. https://doi.org/10.1037//0021-9010.87.2.268

Harter, J. (2018, August 26). Economy: Employee engagement on the rise in the U.S. Gallup. https://news.gallup.com/poll/241649/employee-engagement-rise.aspx

Harter, J. (2021, July 29). U.S. employee engagement holds steady in first half of 2021. Gallup.

https://www.gallup.com/workplace/352949/employee-engagement-holds-steady-first-half-20 21.aspx

Harvard Business Review (2020, December). The impact of employee engagement on performance. 
https://www.achievers.com/resources/analyst-insight/the-impact-of-employee-engagement-on -performance-by-harvard-business-review-analytic-services/

Hobfoll, S. E. (2011). Conservation of resource caravans and engaged settings. Journal of Occupational and Organizational Psychology, 84, 116-122. https://doi.org/10.1111/j.2044-8325.2010.02016.x

Harter, J. K., Schmidt, F. L., \& Hayes, T. L. 2002. Business-unit-level relationship between employee satisfaction, employee engagement, and business outcomes: A meta-analysis. Journal of Applied Psychology, 87(2), 268-279. https://doi.org/10.1037//0021-9010.87.2.268

Hu, J., He, W., \& Zhou, K. (2020). The mind, the heart, and the leader in times of crisis: How and when COVID-19-triggered mortality salience relates to state anxiety, job engagement, and prosocial behavior. Journal of Applied Psychology, 105(11), 1218-1233. https://doi.org/10.1037/ap10000620

Jung, H. S., Jung, Y. S., \& Yoon, H. H. (2020). COVID-19: The effects of job insecurity on the job engagement and turnover intent of deluxe hotel employees and the moderating role of generational characteristics. International Journal of Hospitality Management, 92, 1-9.

Kahn, W. A. (1992). To be fully there: Psychological presence at work. Human Relations, 45(4), 1-23.

Karani, A., \& Mehta, S. A. (2021). "I am ok when you are with me" - Understanding the wellbeing and innovative behavior in the digitized workspace. International Journal of Sociology and Social Policy, 1-20. https://doi.org/10.1108/IJSSP-05-2021-0127

Kerman, K., Korunka, C., \& Tement, S. (in press). Work and home boundary violations during the COVID-19 pandemic: The role of segmentation preferences and unfinished tasks. 1-39. https://doi.org/10.1111/apps. 12335

Khan, A. N. (2021). A diary study of psychological effects of misinformation and COVID-19 threat on work engagement of working from home employees. Technological Forecasting \& Social Change, 171, 1-10. https://doi.org/10.1016/j.techfore.2021.120968

Koekemoer, L., De Beer, L. T., Govender, K., \& Brouwers, M. (2021). Leadership behavior, team effectiveness, technological flexibility, work engagement and performance during COVID-19 lockdown: An exploratory study. SA Journal of Industrial Psychology/SA Tydskrif vir Bedryfsielkunde, 47(0), 1-8. https://doi.org/10.4102/sajip.v47i0.1829

Kotera, Y., Mayer, C. H., \& Vanderheiden, E. (2021). Cross-cultural comparison of mental health between German and South African employees: Shame, self-compassion, work engagement, and work motivation. Frontiers in Psychology, 12, Article 627851, 1-15. https://doi.org/10.3389/fpsyg.2021.627851

Liu, D., Chen, Y., \& Li, N. (2021). Tackling the negative impact of COVID-19 on work engagement and taking charge: A multi-study investigation of frontline health workers. Journal of Applied Psychology, 106(2), 185-198. https://doi.org/10.1037/ap10000866 


\section{Macrothink}

International Journal of Human Resource Studies ISSN 2162-3058 2022, Vol. 12, No. 1

Maslach, C., Schaufeli, W. B., \& Leiter, M. P. (2001). Job burnout. Annual Review of Psychology, 52, 397-422.

Maxwell, J. C. (2007). The 21 indispensable qualities of a leader: Becoming the person others will want to follow. Tennessee, TN: Thomas Nelson.

Mehta, P. (2021). Work from home-Work engagement amid COVID-19 lockdown and employee happiness. Journal of Public Affairs, 1-12. https://doi.org/10.1002/pa.2709

Morgeson, F. P., Mitchell, T. R., \& Liu, D. (2015). Event system theory: An event-oriented approach to the organizational sciences. Academy of Management Review, 40(4), 515-537. https://doi.org/10.5465/amr.2012.0099

Moyo, N. (2020). Antecedents of employee disengagement amid COVID-19 pandemic. Polish Journal of Management Studies 22(1), 323-335. https://doi.org/10.17512/pjms.2020.22.1.21

Nguyen, H. N., \& Tran, M. D. (2021). The effect of perceived organizational support on employee engagement during the covid-19 pandemic: An empirical study in Vietnam. Journal of Asian Finance, Economics and Business, 8(6), 415-426. https://doi.org/10.13106/jafeb.2021.vol8.no6.0415

Ojo, A. O., Fawehinmi, O., Yusliza, M. Y. (2021). Examining the predictors of resilience and work engagement during the COVID-19 pandemic. Sustainability, 13(2902), 1-19. https://doi.org/10.3390/su13052902

Oksa, R., Kaakinen, M., Savela, N., Hakanen, J. J., \& Oksanen, A. (2021). Professional social media usage and work engagement among professionals in Finland before and during the COVID-19 pandemic: Four-wave follow-up study. Journal of Medical Internet Research, 23(6), 1-10.

Ployhart, R. E., Shepherd, W. J., \& Strizver, S. D. (2021). The COVID-19 pandemic and new hire engagement: Relationships with unemployment rates, state restrictions, and organizational tenure. Journal of Applied Psychology, 106(4), 518-529. https://doi.org/10.1037/ap10000917

Poelmann, F. B., Koeter, T., Steinkamp, P. J., Vriens, M. R., Verhoeven, B., \& Kruijff, S. (2021). The immediate impact of the coronavirus disease 2019 (COVID-19) pandemic on burn-out, work-engagement, and surgical training in the Netherlands. Surgery, 719-729. https://doi.org/10.1016/j.surg.2021.02.061

Reinwald, M., Zimmermann, S., \& Kunze, F. (2021). Working in the eye of the pandemic: Local COVID-19 infections and daily employee engagement. Frontiers in Psychology, 12, Article 654126, 1-10. https://doi.org/10.3389/fpsyg.2021.654126

Rožman, M., Sternad Zabukovšek, S., Bobek, S., \& Tominc, P. (2021). Gender differences in work satisfaction, work engagement and work efficiency of employees during the COVID-19 pandemic: The case in Slovenia. Sustainability, 13(8791), 1-17. https://doi.org/10.3390/su13168791 
Sheervalilou, R., Shirvaliloo, M., Dadashzadeh, N., Shirvalilou, S., Shahraki, O., Pilehvar-Soltanahmadi, Y., Ghaznavi, H., Khoei, S., \& Nazarlou, Z. (2020). COVID-19 under spotlight: A close look at the origin, transmission, diagnosis, and treatment of the 2019 nCoV disease. Journal of Cellular Physiology, 8873-8924. https://doi.org/10.1002/jcp.29735

Shin, Y., \& Hur, W. M. (2021). Do organizational health climates and leader health mindsets enhance employees' work engagement and job crafting amid the pandemic? International Journal of Environmental Research and Public Health, 18(12123), 1-18. https://doi.org/10.3390/ijerph182212123

Shuck, B., \& Wollard, K. (2010). Employee engagement and HRD: A seminal review of the foundations. Human Resource Development Review, 9(1) 89-110. https://doi.org/10.1177/1534484309353560

Song, L., Wang, Y., Li, Z., Yang, Y., \& Li, H. (2020). Mental health and work attitudes among people resuming work during the COVID-19 pandemic: A cross-sectional study in China. International Journal of Environmental Research and Public Health, 17(5059), 1-15. https://doi.org/10.3390/ijerph17145059

Stander, F. W., De Beer, L. T., \& Stander, M. W. (2015). Authentic leadership as a source of optimism, trust in the organization and work engagement in the public health care sector. SA Journal of Human Resource Management/SA Tydskrif vir Menslikehulpbronbestuur, 13(1), Article 675, 1-12. http://dx.doi.org/10.4102/sajhrm.v13i1.675

Tan, K., \& Yeap, P. F. (2021). The impact of work engagement and meaningful work to alleviate job burnout among social workers in New Zealand. Management Decision, 1-24. https://doi.org/10.1108/MD-05-2021-0689

Tao, W., Lee, Y., Sun, R., Li, J., \& He, M. (2021). Enhancing employee engagement via leaders' motivational language in times of crisis: Perspectives from the COVID-19 outbreak. Public Relations Review, 48, 1-15. https://doi.org/10.1016/j.pubrev.2021.102133

Torraco, R. J. (2005). Writing integrative literature reviews: Guidelines and examples. Human Resource Development Review, 4(3), 356-367. https://doi.org/10.1177/1534484305278283

Torraco, R. J. (2016). Writing integrative reviews of the literature: Methods and purposes. International Journal of Adult Vocational Education and Technology, 7(3), 62-70. https://doi.org/10.4018/IJAVET.2016070106

Urbancová, H., \& Depoo, L. (2021) Factors affecting strategic types of organizational culture: evidence from organizations and managers operating in the Czech Republic. Management and Production Engineering Review, 12(1), 48-59. https://doi.org/10.24425/mper.2021.136871

Walsh, B. M., Matthews, R. A., Toumbeva, T. H., Kabat-Farr, D., Philbrick, J., \& Pavisic, I. (2019). Failing to be family-supportive: Implications for supervisors. Journal of Management, 45(7), 2952-2977. https://doi.org/10.1177/0149206318774621 


\section{Macrothink}

International Journal of Human Resource Studies

ISSN 2162-3058 2022, Vol. 12, No. 1

Xanthopoulou, D., Bakker, A. B., Demerouti, E., \& Schaufeli, W. B. (2009). Work engagement and financial returns: A diary study on the role of job and personal resources. Journal of Occupational and Organizational Psychology, 82, 183-200. https://doi.org/10.1348/096317908X285633

Yuan, Z., Ye, Z., \& Zhong, M. (2021). Plug back into work, safely: Job reattachment, leader safety commitment, and job engagement in the COVID-19 pandemic. Journal of Applied Psychology, 106(1), 62-70. https://doi.org/10.1037/apl0000860

Zheng, M. X., Masters-Waage, T. C., Yao, J., Lu, Y., Tan, N., \& Narayanan, J. (2020). Stay mindful and carry on: Mindfulness neutralizes COVID-19 stressors on work engagement via sleep duration. Frontiers in Psychology, 11, Article 610156, 1-13. https://doi.org/10.3389/fpsyg.2020.610156

\section{Copyright Disclaimer}

Copyright for this article is retained by the author(s), with first publication rights granted to the journal.

This is an open-access article distributed under the terms and conditions of the Creative Commons Attribution license (http://creativecommons.org/licenses/by/4.0/). 